\title{
Éditorial
}

\section{Les agricultures entre créativité et adaptation responsable}

\section{Jean Semal}

Résidence L'échiquier,

6, Boulevard Dolez,

Boîte B41,

7000 Mons

Belgique

<echiquier.jeansemal@euphonynet.be>

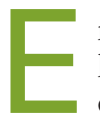
n 1859, entre deux élections, un homme politique trouvait le temps de réfléchir aux grands problèmes de son temps. Battu alors qu'il briguait un siège de sénateur, celui qui devait accéder l'année suivante à la présidence de son pays écrivait ce qui suit: "Chaque feuille d'herbe est un sujet d'étude et produire deux plantes là où il n'y en avait qu'une est à la fois un profit et un plaisir. Et ce ne sont pas les herbes seulement, mais les sols, les semences et les saisons, les fossés et les clôtures, le drainage, la sécheresse et l'irrigation, le labour, la fauche, la mise en gerbes, l'engrangement, les ennemis et les maladies des cultures et tout ce qui peut les préserver et les guérir. Des mille objets de cette nature, chacun constitue un monde d'étude en soi. .

Ce texte d'Abraham Lincoln illustre bien la philosophie qui allait permettre à son pays de devenir un des premiers fournisseurs de produits alimentaires au monde. Qu'en est-il après un siècle et demi, alors que de nouvelles dynamiques s'esquissent dans les rapports entre biosphère et anthroposphère? L'heure serait-elle propice à la prise en compte de cette maxime de Francis Bacon: "On ne commande à la nature qu'en lui obéissant. " ?

À cet égard, l'année 2007 s'est terminée dans le "vert " généralisé, du moins sur le plan de la rhétorique. Vingtième anniversaire du rapport Brundtland sur le développement, Grenelle de l'environnement, Conférence de Bali sur le climat, ont tenu en haleine celles et ceux qui étaient concernés par les rapports entre environnement et développement. Un développement qualifié de " durable ", "soutenable ", ou "viable", tous termes souvent considérés comme interchangeables, alors que les nuances qu'ils expriment méritent réflexion.

L'année 2008 verra-t-elle une meilleure harmonisation des rapports entre les organismes vivants et leur milieu de vie, notamment dans le domaine des agricultures? Telle est la question qui se pose pour donner sens et substance au projet d'une exploitation "raisonnable " de la biosphère.

\section{Les Cahiers Agricultures: une œuvre d'ensemblier}

Les Cabiers Agricultures sont nés en 1992, l'année même de la Conférence de Rio sur le développement et l'environnement. L'Agenda 21, relatif à la programmation décennale d'exploitation de la biosphère, adopté à l'issue de cette Conférence, contient une dizaine de dispositions relatives aux agricultures. Il s'agit notamment de prendre en compte l'ensemble des relations entre organismes et environnements. Écosystèmes, agrosystèmes et anthroposystèmes interagissent, tant dans la mise en œuvre des itinéraires techniques que pour ce qui concerne l'organisation des filières de mise en valeur des produits.

Dans ce contexte, les Cahiers Agricultures se sont vus accrédités par leur comité scientifique dans la fonction d'ensemblier, avec la mission constante d'identifier et d'évaluer les interactions entre les paramètres techno-scientifiques, socioéconomiques et écologiques. Ce cap intégrateur fut maintenu tout au long des quinze années de parution de la revue. Aujourd'hui, après un quart de siècle d'innovations en matière d'ingénierie génétique, avec des applications à grande échelle, on constate que ces découvertes ont essentiellement bénéficié aux systèmes de productions intensives, requérant des investissements élevés pour rendre les environnements à même de répondre aux exigences de plus en plus affirmées 
de génotypes cultivés de plus en plus performants.

En revanche, dans le cas des agrosystèmes peu productifs, pauvres en capacité d'investissements, l'environnement constitue une contrainte peu flexible, avec comme variable d'ajustement, l'hétérogénéité génétique de cultivars rustiques résistants aux stress et adaptés aux milieux.

Aujourd'hui, alors que se fait sentir la nécessité d'accroître la productivité des agricultures marginales et des cultures de subsistance, s'élabore une nouvelle stratégie de gestion de génotypes qui soient à la fois rustiques et productifs.

La philosophie de l'appropriation réciproque des organismes et des environnements prend racine chez les premiers théoriciens de l'agriculture raisonnée, comme en témoigne le "Théâtre d'Agriculture et Mesnage des Champs "d'Olivier de Serres, paru en 1600. Au Xx siècle, elle se structure notamment dans l'œuvre du biologiste René Dubos, dont les écrits plaident pour l'adaptabilité réciproque des partenaires dans la coexistence biocénotique. Un moment récusée dans le contexte de l'agro-taylorisme, cette stratégie reprend force et vigueur pour se concrétiser avec succès dans les travaux contemporains de sélection du riz par le généticien Monty Jones.

\section{Olivier de Serres et le Théâtre d'Agriculture}

Olivier de Serres naît en 1539 à Villeneuve-de-Berg (Ardèche) au sein d'une famille de notables protestants locaux. Orphelin à 7 ans, il est éduqué par des précepteurs et fréquente l'université de Valence. À 19 ans, il vend les terres dispersées de son héritage pour acheter le domaine du Pradel qui compte 150 hectares d'un seul tenant.

S'inspirant des Anciens, Olivier de Serres, définit le premier devoir du "mesnager" dans la conduite d'un domaine: "Bien cognoistre les terres pour les acquérir et les employer selon leur naturel. "Son ambition est de faire partager aux paysans un savoir acquis par observations et expérimentations personnelles afin qu'ils fassent fructifier leurs domaines. Il prône une agriculture scientifique fondée sur l'économie domestique et la gestion rigoureuse. Cette science doit être " entendue par ses principes, appliquée avec raison, conduicte par expérience et pratiquée par diligence".
Passant à l'acte, de Serres remplace la jachère par les amendements et les rotations. Il introduit nombre de nouvelles cultures et développe des outils pour travailler la terre et pour semer. Il construit un système d'irrigation et de drainage muni d'une source artificielle, appelée "mère des fontaines " toujours visible de nos jours, afin de centraliser la gestion de l'eau sur l'ensemble du domaine.

Fort de son expérience, de Serres rédige son "Théâtre d'Agriculture et Mesnage des Champs", comportant un millier de feuillets rédigés en français et traitant des différents aspects de la production et de la consommation agricoles.

En 1599, de Serres se rend à Paris en emportant son texte. Le roi Henri IV prend connaissance de l'ouvrage et s'intéresse à la partie qui se rapporte à l'élevage du ver à soie, qu'il fera imprimer. Cette brochure, largement diffusée dans le royaume, assure la célébrité de son auteur : de Serres trouve bientôt les moyens de publier l'ensemble de son œuvre qui paraîtra le $1^{\text {er }}$ juillet 1600 . L'ouvrage sera réédité huit fois du vivant de son auteur qui s'éteint en 1619, à l'âge de 80 ans.

En 1628, les armées royales mettent à sac et rasent l'hérétique Pradel. Le "Théâtre d'Agriculture" tombe dans l'oubli pour être redécouvert à l'époque napoléonienne. L'édition de 1804, richement annotée par les agronomes du temps, fait le bilan d'une agriculture "réfléchie " aux fonctions multiples, avec un rôle social éminent.

Aujourd'hui, le Domaine Olivier de Serres-Le Pradel héberge un établissement public d'enseignement agricole qui organise régulièrement les "Entretiens du Pradel ". En 2004, sous le titre "Agronomes et Innovations ", on y fit le point sur les enjeux sociaux, économiques et environnementaux des agricultures: après 404 ans, les thèmes favoris d'Olivier de Serres étaient toujours d'actualité...

\section{René Dubos : de I'Agro de Paris au Rockefeller de New-York}

René Dubos est né dans le Val d'Oise avec le $\mathrm{Xx}^{\mathrm{e}}$ siècle. Il est reçu à l'Institut national agronomique de Paris, dont il sort ingénieur en 1921.

En 1927, sur les conseils d'Alexis Carrel, il est recruté à l'Institut Rockefeller de New York pour y étudier le bacille tuberculeux.
En 1932, il identifie le phénomène des enzymes adaptatives, ce qui le conduira à découvrir les effets pharmacologiques de la tyrothricine.

Il met en évidence l'action spécifique d'une enzyme qui décompose la paroi du pneumocoque, ce qui l'amène en 1938 à caractériser le premier antibiotique qui sera breveté en 1940 sous le nom de gramicidine.

En 1941, Dubos est reçu à l'Académie des sciences des États-Unis et, en 1945, il publie une somme sur la cellule bactérienne sous le titre "The Bacterial Cell".

Après une carrière distinguée en tant que bactériologiste et biologiste moléculaire, Dubos s'oriente vers la réflexion en écologie globale. Il prône l'usage du terme "milieu " plutôt que celui d'" environnement " et on lui doit notamment la devise "Penser globalement, agir localement" qui a fait le tour du monde. Le fondement théorique de sa recherche repose sur l'idée d' "humanisation" de la Terre requérant la mise en ouvre de cinq concepts : écologie, économie, énergie, esthétique et éthique, avec lesquels les biosystèmes (dont les agricultures) sont en dialogue permanent.

Dubos publie plusieurs ouvrages qui font date, notamment "So buman an animal", qui lui vaut le prix Pulitzer de littérature en 1969 et qui sera traduit en français en 1972 sous le titre "Cet animal si bumain". En 1972 également, il est chargé, avec Barbara Ward, de préparer le rapport introductif de la première Conférence internationale sur l'environnement qui aura lieu à Stockholm en 1974.

René Dubos dédiera son dernier ouvrage à l'Institut national agronomique "qui m'a formé et qui continue à modeler la terre française". Sa mort en 1982 n'éveillera pas l'attention qu'eut mérité ce précurseur génial de l'explosion biotechnologique et de ses impacts environnementaux.

Le concept d'adaptation de l'homme à son milieu est central dans la philosophie de Dubos. Mais pour lui, la liberté d'adaptation a la responsabilité comme corollaire indispensable: "Le grand problème de notre temps va être de savoir et de décider à quoi nous devons refuser de nous adapter." Et pour cela, il convient de considérer les organismes et les fonctions à partir des usages qui en sont faits, en les replaçant, avec leurs structures génétiques et leurs substrats, dans le système où ils sont appelés à fonctionner. 


\section{Quand I'Afrique montre la voie du " progrès approprié "}

$\mathrm{Au}$ début du $\mathrm{XxI}^{\mathrm{e}}$ siècle, une opération de recherche-développement, placée sous la houlette du Dr Monty Jones, allait se dérouler en Afrique, avec pour prémisses les thèses préconisées par de Serres et Dubos. Monty Jones est né en 1951 en Sierra Leone au sein d'une famille de "cols blancs ". Après un parcours scolaire à Freetown, il s'oriente vers les sciences, contre l'avis de ses professeurs, des religieux irlandais qui le destinaient à la prêtrise. Le petit Monty rêve, depuis sa plus tendre enfance, de pouvoir aider le monde à se nourrir. C'est pourquoi, après avoir conquis une licence en biologie, il poursuit ses études scientifiques au Royaume-Uni, à l'université de Birmingham, grâce à une bourse de la FAO. Il y obtient les diplômes de maîtrise (1979) et de doctorat (1983) et se verra décerner le diplôme de docteur honoris causa par cette même université en 2005. Entre ces deux doctorats se déroule le parcours professionnel de Monty Jones. Il débute dans un poste de sélectionneur à la station rizicole de Sierra Leone, se poursuit dans une fonction de coordinateur au sein de l'Institut international d'agriculture tropicale et aboutit en tant que sélectionneur senior à l'Association pour le Développement de la Riziculture en Afrique de l'Ouest (Adrao) créée en 1971, et devenue, depuis 2003, le Centre du riz pour l'Afrique, regroupant 21 pays.

En 1991, Jones est nommé chef de programme de sélection du riz pluvial. Il propose à l'Adrao de mettre en ouvre des recherches sur le croisement entre le riz asiatique Oryza sativa et le riz africain Oryza glaberrima. Le premier est très productif, répond bien aux intrants, mais est sensible aux facteurs de stress. Le second est peu productif mais très rustique et résistant aux stress biotiques et abiotiques. Ces deux espèces de riz coexistent en Afrique de l'Ouest depuis des siècles sans jamais se croiser et toutes les tentatives pour obtenir des hybrides interspécifiques fertiles avaient échoué jusque-là.

Malgré les réserves de certains responsables de l'Adrao, qui estimaient impossible de mener à bien un tel projet, Jones obtient le feu vert de son institution. Dès lors, les recherches se poursuivront avec l'appui du Groupe consultatif pour la recherche agricole internationale (GCRAI), du Programme des Nations unies pour le développement (Pnud), de la FAO, de la Commission économique pour l'Afrique, de la Banque africaine pour le développement, de la Coopération japonaise, de la Fondation Rockefeller et d'autres encore...

En 1994, Jones réalise une avancée décisive en obtenant des hybrides interspécifiques fertiles et stables. Après sélection, les variétés ainsi obtenues seront dénommées "Nerica " (New Rice for Africa).

Utilisant la technique du sauvetage d'embryons sur milieu de culture contenant du lait de noix de coco, Jones observe pour la première fois que 7 croisements sur 48 produisaient des hybrides stables et fertiles. Ultérieurement, son équipe appliquera avec succès la méthode de culture d'anthères pour accélérer l'obtention de lignées stabilisées. Après multiplication, des milliers de cultivars hybrides de Nerica furent soumis à la sélection participative en milieu paysan. La procédure utilisée comporte trois phases : 1) établissement par l'Adrao de jardins variétaux villageois; 2) sélection paysanne de 5 cultivars qui seront ressemés ; 3) choix par les paysans dans leurs champs de 3 variétés dont les graines serviront pour les cultures subséquentes ; 4) suivi de ces variétés.

Sélectionnées tout d'abord dans les zones de riz pluvial de collines, les variétés de Nerica le furent ensuite pour leur adaptation aux rizières de plaine et sont aujourd'hui cultivées dans des agrosystèmes très divers.

Considérés comme "riz-miracle " par des centaines de milliers de paysans d'une vingtaine de pays d'Afrique, les riz Nerica ont également reçu l'aval de nombreux responsables institutionnels internationaux. Leurs performances sont exceptionnelles sur plusieurs plans: rendements élevés, teneur accrue des graines en protéines, croissance rapide éliminant les adventices (ce qui libère femmes et enfants des travaux astreignants du désherbage), résistance à la sécheresse et aux stress biotiques. Le cycle de production est raccourci, ce qui permet des intercultures de légumineuses, avec enrichissement des sols en composés azotés. Les riz Nerica ont un goût apprécié et fournissent des revenus monétaires autrefois inexistants, avec pour premier résultat une meilleure scolarisation des enfants. La valeur des travaux de Monty Jones a été reconnue non seulement par les paysans et les responsables de la recherche africaine, mais aussi par de nombreuses organisations internationales de recherche et de financement.
En 2000, l'Adrao se voyait décerner le prix Roi Baudouin pour le développement décerné par le GCRAI pour ses travaux sur le riz. En 2002, Jones était nommé secrétaire exécutif du Forum pour la recherche scientifique en Afrique et, en 2004, il devenait cotitulaire, avec le Chinois Yuam Longping, du Prix mondial de l'alimentation, considéré comme le Nobel d'agriculture.

À cette occasion, l'œuvre de Jones fut célébrée comme symbole d'espoir pour des millions de paysans pauvres d'Afrique et considérée comme avancée technologique majeure aux applications parfaitement appropriées à la diversité des situations des producteurs et des consommateurs africains. En disant sa gratitude pour l'attribution du prix, Jones précisa que rien n'eût été possible sans l'appui éclairé de l'Adrao et sans le soutien de ses collaborateurs et amis.

En 2006, le Centre du riz pour l'Afrique recevait le prix des Nations unies pour le partenariat Sud-Sud et, en janvier 2007, Monty Jones se voyait décerner la plaquette d'honneur de l'Adrao. À cette occasion, son génie créateur fut salué par l'ensemble des intervenants, tandis que dans son allocution de remerciements, Jones invitait les chercheurs africains à coopérer davantage en vue de dynamiser leurs efforts communs.

Enfin, cerise sur le gâteau, Monty Jones était récemment retenu par la revue américaine Time Magazine parmi les 100 personnalités les plus influentes de l'année 2007, au moment même où le président Bush disparaissait de la liste.

En juin 2007, j'ai rencontré le Dr Jones lors d'un colloque organisé à Bruxelles par l'Union européenne. Le personnage est affable, souriant et modeste. Sa vision actuelle dépasse largement la riziculture et vise à l'organisation d'une recherche agricole performante et appropriée aux besoins et aux réalités de l'Afrique.

Il y a 20 ans, la docteure Gro Brundtland, qui fut notamment premier ministre de Norvège et directrice générale de l'Organisation mondiale de la santé, rédigeait un rapport qui fit date sur l'avenir écologique de la Terre sous le titre "Notre avenir commun".

Allait-on réaliser le "Village global " ou la "Jungle planétaire"? Aujourd'hui, alors que la question est toujours pendante, Monty Jones nous invite, preuve à l'appui, à surmonter ce dilemme: ni Village ni Jungle, mais réflexion globale et action planétaire dans la recherche et la mise en œuvre du "progrès approprié ". 